\title{
Conflict Management among Malay Married Couples: An Analysis on Their Strategies \& Tactics
}

\author{
Nor Hafizah Abdullah ${ }^{1}$, Nor Azlili Hassan², Abdul Satar Abdullah Harun ${ }^{2}$, Liana Mat Nayan $^{3}$, Rahilah Ahmad ${ }^{4}, \&$ \\ Madihah Md. Rosli ${ }^{4}$ \\ ${ }^{1}$ Faculty of Language and Communication, Universiti Sultan Zainal Abidin (UnisZA), Malaysia \\ ${ }^{2}$ Faculty of Creative Industries, Universiti Tunku Abdul Rahman (UTAR), Malaysia \\ ${ }^{3}$ Faculty of Arts \& Social Sciences, Universiti Tunku Abdul Rahman (UTAR), Malaysia \\ ${ }^{4}$ Faculty of Business \& Management, Asia Pacific University of Technology and Innovation, Malaysia \\ Correspondence: Nor Hafizah Abdullah, Faculty of Language and Communication, Universiti Sultan Zainal \\ Abidin (UnisZA), Malaysia. Tel: 013-399-2928 Email: hafizahabdullah@unisza.edu.my
}

Received: July 31, $2017 \quad$ Accepted: August 17, $2017 \quad$ Online Published: September 28, 2017

doi:10.5539/ass.v13n10p95 URL: https://doi.org/10.5539/ass.v13n10p95

\begin{abstract}
The purpose of this study is to explore the strategies and tactics used in conflict management and analyze their effectiveness based on quantitative methodology. Probability sampling of 300 respondents in Selangor, Malaysia consisting of Malay married couples were selected using cluster sampling. The findings showed that the strategies were competing, collaborating, compromising, avoiding and accommodating. In average, around 80 percent of Malay married couples chose collaborating strategy whereas competing was less popular. However, the most popular tactic among the respondents is trying to do what is necessary to avoid tension which is under the avoiding strategy. Two-way communication and compromise were seen to be the essence in keeping longevity and success in marriage. The study revealed that there was a change in conflict management among Malay married couples which can be related to the economic development of society, technological advances, political scenarios and the influx of foreign culture. Nonetheless, along with the changes in Malaysia's economic system, modern Malay couples are more open-minded. Therefore, couples in this study tend to see conflicts as problems that need to be solved, wanting quality decisions that truly resolve the issues. They believe in the power of consensus and in sharing of information and achieving understanding with one another.
\end{abstract}

Keywords: Conflict management, strategies, tactics, married couple

\section{Introduction}

Conflict is unavoidable process in any marriage. The opposing needs and interests of the couples lie at the primary of marital conflict. Generally, conflict is described as the process that begins when one party identifies that the other one has frustrated some concerns of his/hers (Thomas, 1976); an interpersonal conflict exists whenever an action by one person prevents, obstructs or interferes with the actions of another person (Johnson,1990). In conflict situation, couples show or hide differences in satisfying their individual needs and interests, and they experience interference from their partners in achieving these goals. The way the couples handle conflict is usually described in terms of resolution "strategies" which are interpersonal actions used in the context of relationship to resolve disagreements (Marchand, 2004). The most effective strategy convey advantage to one's self as well as others, ensuring a harmonious relationship and ineffective behavior tries to defeat the other person or avoid issue.

An effective communication is critical for building and maintaining strong couple relationships. Communication is fundamental to human interaction and inevitably in intimate couple relationships. Communication allows a couple to share each other's thoughts and feeling. Their encounter in a situation particularly in a conflict enables them to understand each other's self and reality, as well as their needs and desires. Undoubtedly, according to Barnett and Rivers (1996), communication is an important tool for knowing or emotionally connecting with one another. Both men and women agreed that the emotional connection they shared with their partner was what determined the quality of their relationships and whether they believed they had a good marriage or not. Beehr and Glazer (2001) list praise, positive feedback and approval as examples of emotional support that they argue 
are useful for the development of self-esteem, hence the experience of positive emotions (cited in Rashid, Rahman \& Rahman, 2016).

Conflict in a marriage is a natural part of human life. Hocker \& Wilmot (2001) define conflict as an expressed struggle between interdependent parties over goals which they perceive as incompatible or resources which they perceive to be insufficient. According to Hocker \& Wilmot (2001), conflict involves clashes over what people want or over the means for them to achieve it. For example, party A wants X, whereas party B wants Y. If either of them cannot have what they want at all, or none cannot have what they want to the degree that they would prefer to, conflict will arise. That is why if a couple avoids conflict and pretends not to realize it, this may cause even greater problems in their marriage and also in their life. Nonetheless, conflicts and disagreements between husband and wife are normal in marriage, especially in today's challenging world. If married couples are equipped with basic knowledge and skills in conflict management they will not have significant problems in cases of conflict. Since conflict is an inevitable fact, the most important task of the couple is to prepare the setting necessary for solving conflict and to be prepared against conflict.

In this study, conflict management is defined as the opportunity to improve conflict situations and strengthen relationship. The conflict management can be understood in terms of two key dimensions: assertiveness and cooperativeness. Assertiveness is described as concern with one's own outcomes and cooperativeness as concern with the outcome of others. The research supports the five specific styles of handling conflict which are derived from the combinations of the two dimensions (Thomas \& Kilmann, 1977). The five strategies are namely competition (high on assertiveness and low on cooperativeness), collaboration (high on both assertive and cooperative behavior), compromise (medium on assertive and cooperative behavior), avoidance (low on both assertive and cooperative behavior) and accommodation (low on assertive behavior and high on cooperative behavior). Competition is characterized by the win lose outcome where one person sets to achieve their own way almost regardless of the cost to the other involved. Whereas the collaboration is characterized by openness, exchange of information and attempts to generate win-win solution where the needs of both parties can be met by placing equal emphasis on their own interests and that of the others. Compromise is associated with splitting issues down the middle and mutual concession thus resulting in middle ground solutions which is mutually acceptable by both. Avoidance tends to avoid conflicts altogether, as the name implies. The strategy delays the conflict, and the person does not attempt to satisfy his own point of view or that of others. Then, accommodation is practiced when a person puts aside her own needs and concerns in favor of others.

\section{Literature Review}

The conflict management has also been hypothesized as involving constructive and destructive processes (Deustsch, 1973) and study in the area of marital conflict has focused on these two global aspects of conflict management (Fincham \& Beach, 1999). Constructive processes often include interactions involving cooperation, problem solving behaviors, intensions to learn about the other's needs, willingness to talk about disagreements and a focus on relationship rather than the individual (Hocker \& Wilmot, 1995). In contrast, destructive processes often include interactions that involve manipulation, coercion, escalation and avoidant patterns of domination and subordination. Many researchers have reported on gender differences between male and female on conflict handling strategies.

A research done by Leonard et al. (1989) found that men tended to use compromise strategy and women to use collaboration strategy to resolve conflict with their partners. It was found that women were more likely to use integrating strategy and less likely to use an avoiding strategy with their partners whereas the males were more likely to be obliging with their partner. Conflict management strategy with adolescent girls using problem-solving, withdrawal and compliance more frequently than boys and both sexes scored low on conflict engagement (Minet et al., 2007). The wise strategies must be developed and necessary tactics should be taken before conflicts become detrimental. In discussing the strategies of conflict management, Horney (1945) corresponds that human behavior reflects one of three orientations: moving towards others, moving against others, or moving away from others (cited in Canary, Cupach \& Messman, 1995). For example, a study by Oduro-Frimpong (2007) in conflict management strategy discovers participants' experiences the usage of silence in resolving conflicts with their spouses. Communication skills and conflict tactics are critical in maintaining a healthy marriage. Communication between couples through an aversive manner (e.g. complaining, nagging, or becoming violent until the partner gives in) are harmful to a relationship (Koerner \& Jacobson, 1994, p. 208 in Tam, Lee, Foo, \& Lim, 2011). According to Baucom, Notarius, Burnett and Haefner (1990), husband and wives differ in their communication skill, particularly the tactics in handling conflicts. For example, husbands are more likely than wives to withdraw in a communication that relates to problem-solving. Besides, Tamara and Donald (1993) asserted that the negative communication from no distressed husbands is an indication of constructive 
engagement which involved handling of conflict tactic in a marital adjustment (in Tam, Lee, Foo, \& Lim, 2011). Buehler et al. (1998), also found that conflict tactics that involve with physical and verbal aggression are most likely to cause a marital conflict. Hence, inappropriate communication skills and conflict tactics adopted in dealing with conflicting issues in a marital relationship will almost invariably results in decline in marital satisfaction (in Tam, Lee, Foo, \& Lim, 2011).

However, Pearson (2001) claimed that women and men also appeared to handle conflict differently. Based on many studies, Pearson finds that in the fight-or-flight pattern common to most animals, men are perhaps surprisingly more apt to take flight, whereas women are willing to engage in fight. When women do engage in a verbal argument, they are more likely to do indirect strategies, whereas men are more in use of direct strategies. Another research finds significant gender differences in interpersonal conflict (Krolokke \& Sorensen, 2006; Wood, 2010). For example, men are more apt to withdraw from a conflict situation than are women. It has been argued that this may be due to the fact that men become more psychologically and physiologically aroused during conflict (and retain this heightened level of arousal much longer) than do women, and so may try to distance themselves and withdraw from the conflict to prevent further arousal (Goleman, 1995b; Gottman \& Carrere, 1994; De Vito, 2016). Women, on the other hand, want to get closer to the conflict; they want to talk about it and resolve it. Even adolescents reveal these differences. In research on boys and girls aged 11 to 17 , boys withdrew more than girls (Heasley, Babbitt, \& Burbach, 1995; Lindeman, Harakka, \& Keltikangas-Jarvinen, 1997; Devito, 2016). Other research have found that women are more emotional and men are more logical when they argue. Women have been defined as conflict "feelers" and men as conflict "thinkers" (Sorenson, Hawkins, \& Sorenson, 1995). Another difference is that women are more apt to reveal their negative feelings than are men (Canary, Cupach, \& Messman, 1995; Schaap, Buunk, \& Kerkstra, 1988; DeVit0, 2016).

In particular, conflict-management strategies are integral to the success of a marriage. Some scholars contend that how couples argue is a stronger predictor of the health of their relationship than what they actually argue about (Afifi \& Hamrick, 2006). In managing conflict, there are various strategies that can be used. We need to realize that the strategies we choose will be influenced by a variety of factors, such as the goals to be achieved, our emotional state, our cognitive assessment of the situation, our personality and communication competence, and our family history (Koerner \& Fitzpatrick, 2002; DeVito, 2016) and maybe the strategies chosen will impact on the future. Understanding these factors may help us select strategies that are more appropriate and effective. Research finds that using productive conflict strategies can have lots of beneficial effects, whereas using inappropriate strategies may be linked to poorer psychological health (Neff \& Harter, 2002; Weitzman, 2001; Weitzman \& Weitzman, 2000; DeVit0, 2016). Cartensen, Gottman \& Levenson (1995) suggested that couples would remain married and avoid divorce if they could successfully manage their interaction to maximize positive outcomes.

To note, there were still very limited studies reporting on the conflict management strategy and tactic among the Malay married couples in Malaysia. Little is known on how Malay married couples deal with conflict in their marriage. There was lack of an empirical research conducted in the areas in Malaysia. With the divorce rate on the rise due to social, economic and psychological factors, deeper understanding on how Malaysian couples interact during various conflict situations would lead to a better designed counseling techniques and skills by the relevant authorities. Hence, in the present study, the main objective was to identify the conflict management strategy and tactic adopted by the Malay husbands and wives in managing conflict in their marital relationship. The research addresses the question regarding the factors which were associated with the observations of conflict management strategies and tactics of respondents who have been together for many years. It is hoped that by understanding strategies and tactics used among Malay married couples, new information could be developed especially in the way married couples interact during conflict (as Malaysia is a multiracial and multicultural country) where Eastern values and traditions still hold sway. This research can also reveal negative communication patterns that may help towards encouraging awareness which may result in a reduction of divorce rates, from which these findings will help formulate tools that marriage counselors will be able to apply and assist afflicted married couples in the best possible way.

\section{Theoretical Framework}

Interpersonal communication involves more than simply transferring or exchanging messages. It is a complex process of creating meaning in the context of an interpersonal relationship. In order to understand this process more fully, a model is needed to be studied in determining the effectiveness of communication. The oldest model of human communication process that has been introduced by Lasswell (1948) as cited in Wood (2014) and has been improved by Shannon \& Weaver (1949) is engaged in this study. Linear model of communication is specially designed to develop effective communication between sender and receiver. At first, the model was 
developed to improve the Technical communication. Later it is widely applied in the field of communication and will be used in this study as the theoretical framework

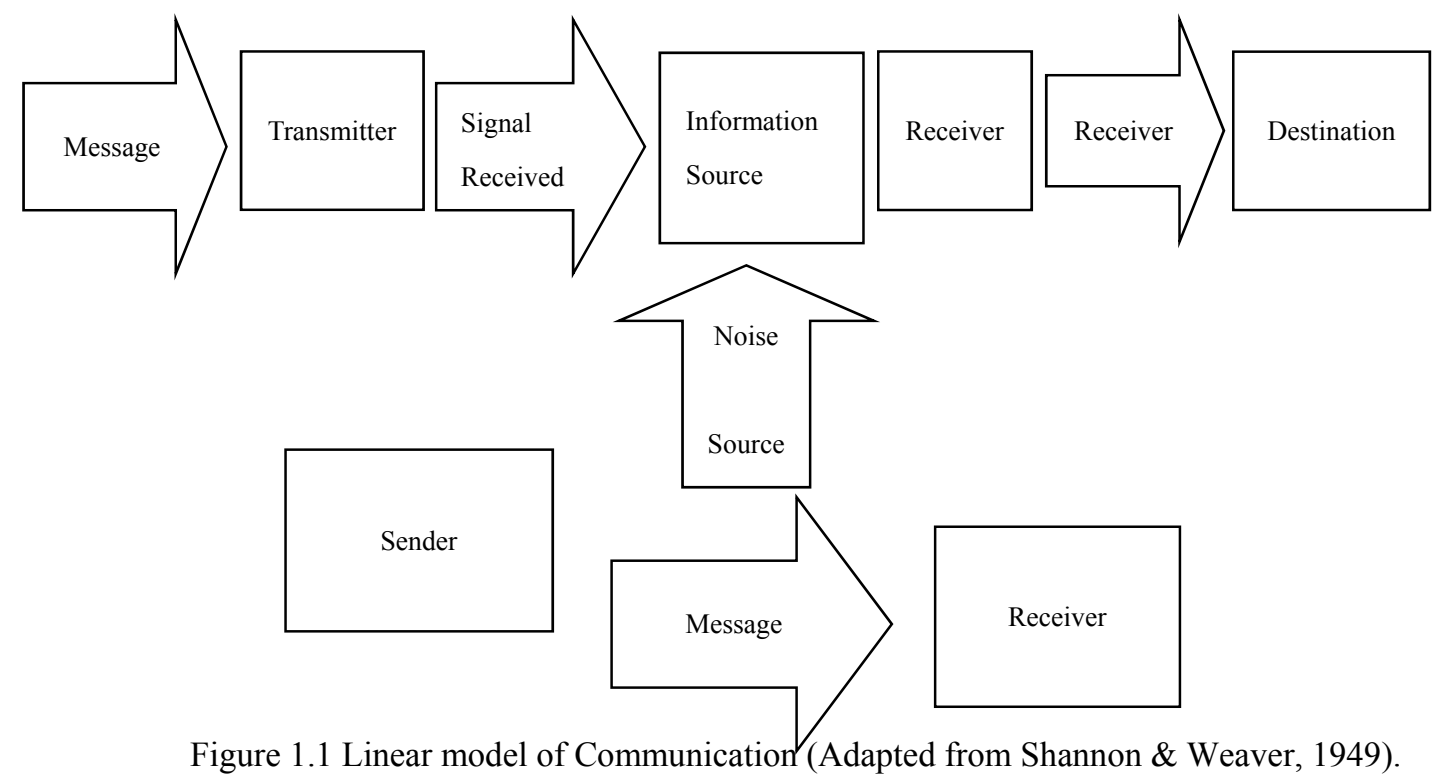

The elements of this model consist of Who? Says what? In what channel? To whom? and With what effect?. The new element that has been introduced by Shannon \& Weaver (1949) as cited in De Vito (2016) is noise. Types of noise can be divided into 4 categories:

\begin{tabular}{|c|c|c|}
\hline Types of Noise & Definition & Examples \\
\hline Physical & $\begin{array}{l}\text { Interference that is } \\
\text { external to both speaker } \\
\text { and listener }\end{array}$ & $\begin{array}{ll}- & \text { Screeching of passing cars } \\
- & \text { Hum of computer } \\
- & \text { Sunglasses } \\
- & \text { Garbage on your computer } \\
- & \text { Pop-ups and banner ads }\end{array}$ \\
\hline Physiological & $\begin{array}{l}\text { Physical barriers within } \\
\text { the speaker or listener }\end{array}$ & $\begin{array}{ll}\text { - } & \text { Visual impairments } \\
\text { - } & \text { Hearing loss } \\
\text { - } & \text { Articulation problems } \\
\text { - } & \text { Memory loss }\end{array}$ \\
\hline Psychological & $\begin{array}{l}\text { Cognitive or mental } \\
\text { interference }\end{array}$ & $\begin{array}{l}\text { [1]. Biases and prejudices in senders and receivers } \\
\text { [2]. Closed-mindedness } \\
\text { [3]. Inaccurate expectations } \\
\text { [4]. Extreme emotionalism (anger, hate, love, grief) }\end{array}$ \\
\hline Semantic & $\begin{array}{l}\text { Speaker and listener } \\
\text { assigning different } \\
\text { meanings }\end{array}$ & $\begin{array}{ll}- & \text { People seeking different languages } \\
- & \text { Use of jargon or overly complex terms not understood by listener } \\
- & \text { Dialectical differences in meaning }\end{array}$ \\
\hline
\end{tabular}

Therefore, the element of noise (with its various types) needs to be removed in order to gain effective communication. Hence, this model can provide transactional approach to communication and helps to understand the nature of communication. In addition, the change in any aspect of communication system (source, message, channel, receiver, context, feedback, etc.) has a potential to influence the communication process in interpersonal communication. This model is in fact can be applied in various aspects of daily life communication especially in determining the right strategies and tactics in managing conflict.

Conflict can be defined as a process in which one party perceives that its interest are being opposed or negatively affected by another party (Wall, 1995). Clearly, when we are in conflict, we are unable to see the good or bad a person is, because we are now having an unpleasant feeling towards the person, which we can relate it to the type of noise, called psychological. When you are having conflict with someone, there will be high possibility that the message sending between both of you will be ignored or misinterpreted, and this will encourage the failure of the communication process. 
In discussing about conflict in marriage, Buehler et al. (1998) defines marital conflict as the existence of high levels of disagreement, stressful and hostile interactions between spouses, disrespect, and verbal abuse. Then, Rose et al. (2007) concluded that the common theme dominant in all definitions about conflict are the aspects of differing needs, goals or interests and the perceived or real interference from one party unto the other party to achieve these needs, goals or interests.

Several factors have been identified as the causes of marital conflict including failure of discharging commitments among husband and wives, lack of spiritual support from the perspective of religion, financial problems, sexual problems, incompatibility, interference due to communication issues and others (Tam et al., 2011). However, the factors of marital conflict are not the focus of this study. By referring back to the type of noise which is psychological, marital conflict which is falling under this type of noise, should be focuses on to investigate the proper way or method to manage marital conflict. Through identification on the better way to manage marital conflicts, divorce, as the final result of failure solution of marital conflict could be avoided.

\section{Research Methodology}

The research design was chiefly exploratory assessing the Malay married couple's conflict management strategies and conflicts. Responses from 150 Malay married couples (i.e. 150 husbands and the wives) were obtained through survey using questionnaires. It was distributed to all areas in Selangor, Malaysia. Respondents were informed that participation was voluntary and information they provided would be kept confidential. Questions in the survey included the following areas: demographics as well as strategies and tactics in managing conflict in their marital relationship. Descriptive statistics was used to analyze the data by using Statistical Package for Social Sciences (SPSS). The research implemented the Thomas Kilmann MODE Instrument which was developed by Thomas and Kilmann (1977) to measure the strategies and tactics of conflict management adopted by the Malay married couples to resolve conflict in their marital life. The respondents were asked to choose the statements in each pair that best described their behavior in conflict situations. The scale included 5 subscales which were considered as the strategies and tactics of conflict management. The strategies and tactics include: competition (try not to hurt his/her feelings), collaboration (made some efforts to solve problems), compromise (exchange the ideas with spouse), avoidance (try to do what is necessary to avoid tensions) and accommodation (sacrifice own needs to fulfill spouse needs).

\section{Results and Discussion}

There are 150 married couples responded to the questionnaire in this research. The demographic information of the respondents is presented in Table 1. The characteristics of the couples in Table 1 indicated that the age of couples ranged between 25 and 59 years. Around 80 per cent of respondents belonged to the age category of 25-39 and 40-49 years followed by 20 per cent belonged to the age category of 50-59 years. The main purpose of the present study was to identify what kind of conflict management strategies and tactics the Malay married couples use. Furthermore, the relationship of age and length of marriage and its association with different conflict management strategies and tactics were also observed.

Table 1. Demographic Information of Sample $(\mathrm{n}=300)$

\begin{tabular}{|c|c|c|c|}
\hline Items & Information & $\mathrm{n}$ & $\%$ \\
\hline \multirow{2}{*}{ Gender } & Male & 150 & 50 \\
\hline & Female & 150 & 50 \\
\hline \multirow{3}{*}{ Age (Years) } & $25-39$ & 120 & 40 \\
\hline & $40-49$ & 120 & 40 \\
\hline & $50-59$ & 60 & 20 \\
\hline \multirow{3}{*}{ Periods of marriage (Years) } & $6-10$ & 120 & 40 \\
\hline & $16-20$ & 120 & 40 \\
\hline & above21 & 60 & 20 \\
\hline
\end{tabular}

\subsection{Strategies}

In identifying strategies, on the whole, collaborating strategy is the most popular strategy practiced by the Malay married couples, whilst the least popular strategy is competing in solving issues with their spouses. Collaborating strategy is more effective in most of the situations as it would satisfy both partners' concerns and calm down the conflicting situation quickly. Overall the results clearly reveal that couples adopted collaboration strategy over competition. This may be attributed to the fact that both the couples in conflict situation react by involving in 
mutual exchange of thoughts and feelings so that needs and interests of both the couples are fulfilled and sacrificing their own needs and interests to satisfy their spouses needs since they may have fear of losing their relationship and they don't want to hurt the feeling of their partner in conflicting situation.

Collaboration is the most common strategy mentioned during conflict among Malay married individuals in Malaysia. People will react positively through any conflict if they are satisfied with their relationship. Being collaborative during conflict leads to a better outcome and increases marital satisfaction and relationship stability (Kelly, Finchem \& Beach, 2003). In a harmonious relationship, spouses are able to clarify their expectations through communication. They can express personal thoughts and feelings, which may lead to greater feelings of intimacy. They will feel free to openly address issues that concern them. They also tend to be more open and collaborative in their conflict management (Christensen \& Shenk, 1991).

\subsection{Tactics}

Based on the research, about $92.6 \%$ of respondents try to do what is necessary to avoid tensions. It shows that this tactic has been the most popular among others. The second most popular tactic is to make some efforts to solve any problem arises $(88.5 \%)$. Trying not to hurt each other's feelings becomes the third tactic used by the respondents (87.8\%) in managing the conflict with their spouses. As shown in Table 3, the lowest percentage of $15.5 \%$ shows that the couples feel stress to get their points to be agreed upon by the spouse. Perhaps due to the culture and norms, only $25.1 \%$ of the respondents agree satisfying all their needs. However, $26.6 \%$ of them try to postpone the issue until they have some time to think about it.

Table 2. Tactics used by Malay married couples in managing conflicts in the marital relationship

\begin{tabular}{ll}
\hline Item & Percentage (\%) \\
\hline Tried to do whatever necessary to avoid tensions & $92.6 \%$ \\
Made some effort to solve any problem & $88.5 \%$ \\
Tried not to hurt his or her feelings in managing conflicts with their spouses & $87.8 \%$ \\
Tried to postpone the issue until they have some time to think about it & $26.6 \%$ \\
Agreed about concerning with satisfying all their needs & $25.1 \%$ \\
Stressed to get their points to be agreed upon by the spouse & $15.5 \%$ \\
\hline
\end{tabular}

\subsubsection{Age \& Tactics}

In examining the relationship between age and tactics practiced by the Malay married couple, there are several elements that have captured the attention of the researchers. The respondents with the age range of 25-49 years demonstrate that they rather try less to show their spouse the logic and benefits of their ideas. Whereas the respondents within the age range of 50-59 years are the utmost ones having stress to get their points across to be agreed by their spouses. They are also the least couples who try to find a fair combination of gains and losses for both parties.

Findings indicate that younger individuals increased intimacy as compared to the other category of age (Camara \& Resnik 1989). The short period of their marital life maybe the factor that they are still in romantic and exploration phase. They may face less conflict and other relationship issues and may feel the need to keep investing in their relationship. On the other hand, it is possible that couples with many years of marriage may take their partners for granted, which in turn may influence their conflict management tactics.

\subsubsection{Periods of Marriage \& Tactics}

The respondents within the period of 16-20 years of marriage were the least to consistently seeking their spouses in working out a solution. They were also the least to attempt to get all concerns and issues immediately. Furthermore, these groups of respondents are also the least to try to find a fair combination of gains and losses for both parties. The study also reveals that respondents within 6-10 years of marriage were the highest in rate for letting their spouses to take responsibility to solve problems whilst the respondents within 21 years of marriage and above were the least to let their spouses to maintain his or her view if it makes them happy. This group is also the least to sacrifice their own needs to fulfill their spouse needs.

\subsubsection{Gender \& Tactics}

Between genders, the research found that the males compared to females stress more to get their points to be agreed upon by their spouses. The females will make some efforts to solve any problem as compared to males and they will also try to find combination of gains and losses for both parties. However the males will try to 
postpone the issue until they have some time to think about it as compared to the females. In some way, the researchers find that females will try not to hurt their spouses' feelings. It clearly means that the married couples were more or less similar in expression of their behaviors. The couples were not dominating in nature and they did not involve in win-lose arguing or neither the husbands nor the wives sets to achieve their own way at the cost of their partners. It can be argued that, husbands often react to conflict situation by involving in open and direct discussion of the problem and are often considerate of satisfying the needs of both the parties in conflict situation.

Furthermore, the findings bring out that husband and wives were low on the behaviors involving give and take, accepting loss and gains, encouraging compensation and solutions which are mutually acceptable. Husbands had avoided the face to face discussion of thoughts and feelings with their wives and were most likely to let their wives take the responsibility of solving the problem. This may be due to the fact that the wives gender role tendency to concern for others, role expectation and their tendency to take care of husbands. The data is in accordance with the findings of Brahman et al. (2005) who claimed that men and women tend to endorse conflict handling strategies that complement gender role expectations in handling conflicts, women unlike men, favor accommodating strategies. Men prefer to be more collaborating and avoiding in their style of conflict handling which accords precisely with gender role expectations, as they are expected to remain cool and in control (Haferkamp, 1991). They also experience anxiety in social settings which may make them more likely than women to avoid conflict. These include ignoring and walking away from the conflict situation. In a country like Malaysia, generally men employ more influence than women. Malaysian women still abide by traditional, cultural and religious values where the husband is the head of the household and is considered one notch above (Noraini M. Noor, 1999). Give in or walk away when conflict occurs is an example of avoidance patterns and is most probably the best way for wives to defer to their husbands.

Hence, the husbands were seemed to become more of collaboration adopters and wives were accommodation adopters. The results were according to their gender role expectation where husbands think and act on problem situation providing justice to both the partners whereas wives accordingly with their gender role expectation sacrifice their needs for the sake of others. This showed the need of providing proper control to the wives in handling the work and family conflicts and derive greater marital as well as job satisfaction.

\section{Conclusion}

Conflict is a natural part of human life. If a couple intentionally avoids a conflict and pretends not to be aware and realize it, this may cause even greater problems. Conflicts and disagreements between husbands and wives are rather a norm but if couples are equipped with at least the basic knowledge and skills on conflict management they will not have significant problems in encountering conflicts.

The economic development of Malaysian society and the influx of foreign culture impose great challenges in Malay marriages. Along with the escalating changes in Malaysian economic, political, technological and social systems, modern Malay married couples are more educated and open minded. The development of information technology plays a very evident role in this context. It has dramatically increases communication strategies and tactics among people from all walks of life. The value and norm of marriage from traditional culture has gradually been replaced. Modern Malay married couples are more likely to value the quality of marriage rather than enduring an unhappy relationship. As evident in this study, most of the respondents are more actively in search of support and solutions in remedying conflicts in their marriages. They tend to see conflicts as problems that need to be solved. They want quality decisions that truly resolve the issues. They do not only believe in the power of consensus but also in sharing of information among themselves with the ultimate aim to understand each other more truly and sincerely.

The present research suggests that the periods of marriage and age of partners play an important role determining conflict management strategies and tactics of Malay married couples. Results show no gender differences among the couples in their use of conflict management strategies and tactics. It can be concluded that there were no preferred strategies and tactics of conflict management among the Malay husbands and wives in our sample. However considering the limitations of the research regarding the number of the participants, it is suggested that this type of research may be conducted on a larger sample from different social classes to have conclusive results. This study will be helpful in the study of family and marriage relationship as well as in social psychological understanding of the conflict management strategies and tactics in close relationships. It can helpful for social workers, counselors and therapies to understand how attachment patterns are associated with the conflict management strategies and tactics to design effective intervention techniques. 


\section{References}

Afifi, T. D. \& Hamrick, K. (2006). Communication processes that promote risk and resiliency in postdivorce families. In Fine, M. A. \& Harvey, J. H. (Eds.), Handbook of Divorce and Relationship Dissolution. (pp. 435-456). New Jersey: Routledge.Babbie, E. (2001). The practice of social research. USA: Warsworth Thomson Learning. https://doi.org/ 10.4324/9781315820880.ch21

Baucom, D. H., Notarius, C. I., Burnett, C., \& Haefner, P. (1990). Gender differences and sex role identity: Implications for marital interaction. In The Psychology of Marriage: Conceptual, Empirical, and Applied Perspectives, ed. F. D. Fincham \& T. Bradbury, (pp. 150-171). New York: Guilford Press. https://doi.org/ 10.1007/BF0028980

Buehler, C., Krishnakumar, A., Stone, G., Anthony, C., Pemberton, S., Gerard, J., \& Barber, K. (1998). Interparental conflict styles and youth problem behavior: A two sample replication study. Journal of Marriage and the Family Building skills: Communication the communication barriers leading to divorce (n.d.). https://doi.org/10.2307/353446

Brahman, S. D., Margavio, T. M., Hignite, M. A., Barrier, T. B., \& Chin, J. M. (2005). A gender-based categorization for conflict resolution. Journal of Management Development, 24(3), 197-208. https://doi.org/ $10.1108 / 02621710510584026$

Camara, K. A., \& Resnick, G. (1989). Styles of conflict resolution and cooperation between divorced parents: Effects on child behavior and adjustment. American Journal of Orthopsychiatry, 59(4), 560-575. https://doi.org/ 10.1111/j.1939-0025.1989.tb02747.x/pdf

Canary, D. J., Cupach, W. R. \& Messman, S. J. (1995). Relationship conflict: Conflict in parent-child, friendship, and romantic relationships (2nd ed). California: Sage Publications.

Carstensen, L., Gottman, M., \& Levenson, W. (1995). Psychology and Aging, 10(1), 140-149. http://dx.doi.org/10.1037/0882-7974.10.1.140

Christensen, A. \& Shenk, J. L. (1991). Communication, conflict, and psychological diastance in nondistressed, clinic and divorcing couples. Journal of Consulting and Clinical Psychology, 59(3), 458-463

Deutsch, M. (1973). The Resolution of Conflict: constructive and destructive processes. Yale University Press, New Haven.

DeVito, J. A. (2016). The Interpersonal Communication Book (14th ed.). USA: Pearson Education.

Fincham, F. D., \& Beach, S. R. H. (1999). Conflict in marriage: Implications for working with couples. Annual Reviews Psychology, 50, 47-77. https://doi.org/ 10.1146/annurev.psych.50.1.47

Haferkamp, C. J., (1991). Orientations to conflict: gender, attributions, resolution strategies, and self monitoring, Journal of Current Psychology, 10(4) 227-240. https://doi.org/ 10.1007/BF02686895

Hocker, J. L., \& Wilmot, W. W. (1995). Interpersonal Conflict. Brown \& Benchmark Publishers, Madison Wisconsin, Dane.

Hocker, J. L., \& Wilmot, W. W. (2001). Interpersonal conflict (6th ed.). New York: McGraw-Hill

Johnson, D. W. (1990). Culture and the development of conflict resolution style. Journal of Cross Cultural Psychology, 13(1), 43-58. https://doi.org/ 10.1177/0022022182131005

Kelly, A. B., Fincham, F. D., \& Beach, S. R. H. (2003). Communication skills in couples: A review and discussion of emerging perspectives. In J. O. Greene, B. R. Burleson (Eds.), Handbook of communication and social interaction skills (pp. 723-751). Mahwah, NJ: Erlbaum.

Koernor, K., \& Jacobson, N. S. (1994). Emotion and behavioral couple therapy. In S. M. Johnson and L. S. Greenberg (Eds.), The Heart of the Matter: Perspectives on Emotion in Marital Therapy (pp. 207-226). New York: Brunner/Maze.

Laswell, H. (1948). The Structure and Function of Communication in Society. New York: Harper and Row.

Leonard, H., Chusmir, \& Mills, J. S., (1989), Gender differences in conflict resolution styles of managers at work and at home. Journal of Sex Roles, 20(3/4), 149-163. https://doi.org/ 10.1007/BF00287988

Marchand, J. (2004). Avoidance and attacking conflict-resolution strategies among married couples: Relations to depressive symptoms and marital satisfaction. Journal of Family Relations, 49(2), 201-206. https://doi.org $/ 10.1111 / \mathrm{j} .1741-3729.2000 .00201$ 
Minet,de. W., Susan, J. T., \& Wim, H. J. (2007). Empathy and conflict resolution in friendship relations among adolescents. J. Aggressive Behavior, 33, 48-55. https://doi.org/10.1002/ab.20166

Noraini M Noor (1999). Roles and women's well-being: Some preliminary findings from Malaysia. Sex Roles, 41(3/4), Academic Research Library, 123. https://doi.org/10.1023/A:1018846010541

Oduro-Frimpong, J. (2007). Semiotic silence: Its use as a conflict-management strategy in intimate relationships. Semiotica, 167(1-4), 283-308. https://doi.org/10.1515/SEM.2007.080

Pearson, J. C. (2001). The Language of Conflict and Resolution (Eadie, W. F. \& Nelson, P. E, Eds.): California: Sage Publications.

Rashid, R. A, Rahman, M. F., \& Rahman, S. B. (2016). Teachers' engagement in social support process on a networking site. Journal of Nusantara Studies, 1(1), 34-45.

Rose, R. C., Suppiah, W.RRV, Uli, J. \& Othman J. (2007). A face concern approach to conflict management- A Malaysian perspective. Journal of Social Science, 2(4), 121-126. https://doi.org/10.3844/jssp.2006.121.126 •

Schaubhut, N. A. (2007). Technical Brief for the Thomas-Kilmann Conflict Mode Instrument: Description of the Updated Normative Sample and Implications for Use. Retrieved July 9, 2009, from https://www.cpp.com/products/tki/index.aspx.

Shannon, C. \& Weaver, W. (1949). The Mathematical Theory of Communication. Urbana: University of Illinois Press.

Tam, C. L., Lee, T. H., Foo, Y. C., \& Lim, Y. M. (2011). Communication skills, conflict tactics and mental health: A study of married and cohabitating couples in Malaysia. Asian Social Science, 7(6), 79-87. http://doi.org/10.5539/ass.v7n6p79

Tamara, G. S., \& Donald, H. B. (1993). Marital communication: Differences among maritally distressed, depressed, and nondistressed-nondepressed couples. Journal of Family Psychology, 7(1), 148-153. http://doi.org/10.1037/0893-3200.7.1.148

Thomas, K. W. (1976). Conflict and conflict management, Handbook of Industrial and Organizational Psychology, Ed. M. Dunnet., RandMcNally, Chicago. pp. 889-935.

Thomas, K. W., \& Kilmann, R. H. (1977). Developing a forced choice measure of conflict-handling behaviour: The MODE instrument. Journal of Educational Psychological Measurement, 37, 309-325. http://doi/abs/10.1177/001316447703700204

Wood, J. T. (2010). Interpersonal Communication: Everyday Encounters. 6th Edition. United States of America: Thomson Wadsworth.

Wood, J. T. (2014). Interpersonal Communication: Everyday Encounters. $8^{\text {th }}$ Edition. United States of America: Thomson Wadsworth.

\section{Copyrights}

Copyright for this article is retained by the author(s), with first publication rights granted to the journal.

This is an open-access article distributed under the terms and conditions of the Creative Commons Attribution license (http://creativecommons.org/licenses/by/4.0/). 